\title{
The Relationship between Service Quality Dimensions And Customer Satisfaction in Public Service Organizations With Application to EgyptAir
}

\author{
Dr. Marwa Gaber Ahmed Fahim \\ Lecturer in Business Administration Department \\ Modern Academy for Computer Science and \\ Management Technology in Maadi \\ Arab Republic of Egypt
}

\begin{abstract}
It is obvious that customers are essential stakeholders in organizations and their satisfaction is a priority to the management. Satisfying customers by ensuring good quality services is the latest organizational strategy in today's business world. So, service quality nowadays has become ever more important to the achievement of customer satisfaction and competitive advantage as well. This coupled with the mounting complexities of the needs and expectations of customers in general. Prior research has suggested that customers' expectations and perceptions are more likely to be different across service sectors. Additionally, much of the research conducted about this theme has concentrated on the private sector. However, public sector organizations, especially in developing countries, play more dominant roles in service delivery. For that reason, the primary purpose of this study is to examine the relationship between service quality and customer (citizen) satisfaction in public service sectors with respect to service quality dimensions. The paper aims at identifying the determinants of service quality from the customers' perspective, and how they affect their satisfaction. The SERVQUAL tool developed by Parasuraman, et al. (1988) was used with its five dimensions (tangibility, reliability, responsiveness, assurance, and empathy), to find out how applicable it is in the context of the public sector. Empirically, the paper explores the relationship between service quality dimensions and customer satisfaction at EgyptAir. Finally, the research provides useful and beneficial findings and recommendations which can be adopted by public service providers, in an attempt to build up and promote sustainable quality and successful customer satisfaction strategies, particularly in the Egyptian public sector.
\end{abstract}

Keywords: Service Quality, Perceived Service Quality, Service Quality Dimensions, SERVQUAL Model, Customer Satisfaction, Customer Expectation, Customer Perception, Service Sector, Public Services, Public Service Organizations, EgyptAir.

\section{Introduction}

Quality is nearly-transparent when it is present, but easily-recognized when it is absent. Service quality in general is considered the most vital aspect that contributes to the establishment and evolution of credibility and reputation of an organization in the eyes of people (Ali \& Yaseen; 3), and the most essential criteria for satisfying customers, and then enhancing organizational performance, success, and profitability. (Kotler, et al., 2002: 391) state that winning in today's marketplace requires the need to build customer relationship, which means deliver-

* This article was submitted in June 2017, and accepted for publishing in September 2017. 
ing superior value over other competitors to the customers. Hence, service quality and customer satisfaction are major concepts that organizations must consider to remain competitive in the business environment these days. Also, it is very important for organizations to know well how to measure those constructs from the customers' perspective in order to better understand their needs, desires, expectations, and thus satisfy them.

Therefore, service quality and customer satisfaction have been subjects of senior interest to organizations and intellectuals as well. It has been proven by many researchers that service quality is related to customer satisfaction; is that customers' satisfaction relies on the quality of services delivered, and at the same time determining whether an organization provides quality products or not depends on customers' feedback about the satisfaction they obtain from consuming these products (Kotler \& Keller, 2009: 169). But, are customers satisfied because of service quality only? \& what about the relationship between customer satisfaction and service quality dimensions?... all are questions need to be more-highlighted.

Despite the criticality of service quality to businesses, measuring quality often causes difficulties to service providers because of the unique attributes of services. In sight of this, services need a distinctive framework for quality determination and measurement. Among major frameworks, the SERVQUAL model developed by Parasuraman, et al. $(1985,1988)$ appears to be the most preferable and widely-used model for measuring service quality, and thereby satisfaction in the service industry (El-Saghier \& Nathan, 2013: 1-2).

On the other hand, public sector organizations are accountable to their communities and to their customers (citizens) alike. Public service providers, as any service provider, are required to offer high-quality services to people in order to guarantee citizen satisfaction, with a difference that limited funding is available. This is a matter of concern to the public since they are taxpayers and their taxes are used to finance these public sector organizations, thus they expect that good services should be provided to them in return. In spite of that, a lot of public organizations lack the culture, processes, and systems to deliver high-quality services. In addition, it is widely-recognized that public sectors, especially in developing countries, face particular complexities in achieving and measuring service quality. According to Gowan, et al. (2001); service provision is more complex in the public sector than in the private sector because it is not simply a matter of meeting expressed needs but of discovering unexpressed ones (Kumasey, 2014: 175). In this context, it is clear that the impact of the ongoing economic and administrative reform process in Egypt has been experienced by almost all sectors. The entry of the private sector in Egypt during the last few decades, coupled with liberalization and globalization, has posed massive challenges to the public sector organizations in retaining their customers.

In short, although the concepts of service quality and customer satisfaction have been used so many times in literature, but the relationship between both of them is still quite ambiguous. Therefore, the main objective of this research is to study the linkages between these two concepts, as it intends to examine the factors leading to customer satisfaction in terms of service quality. The study investigates the causal relationship between service quality and customer satisfaction in the public sector with respect to the five dimensions of the SERVQUAL model (tangibility, reliability, responsiveness, assurance, and empathy). As well as, the paper provides a modest attempt not only to assess the customer perception in relation to expectations regarding various service quality dimensions, but also to analyze the influence of perceived service quality (the gap between expectations and perceptions) on customer satisfaction at a large and important public service organization in Egypt, which is EgyptAir. Eventually, the research makes some useful recommendations that could be adopted by public service providers, especially in Egypt, to keep and satisfy their customers. 


\section{Theoretical Framework}

\section{Problem Statement}

In today's increasingly-sophisticated and changing environment, service quality has been recognized as the most powerful competitive weapon of the organization. In fact, service quality offers an excellent strategy for survival and success. Furthermore, much of the research has confirmed that customer satisfaction also contributes to the overall performance. Consequently, service sectors must have the ability to understand the specific needs of customers and to address them in well-mannered behaviors (Akhtar, et al., 2016: 537).

In general, the service industry plays a prominent role in the economy of many countries. In today's global competitive markets, providing quality services is important to business sectors. Even the public sector organizations have come under a rising pressure to deliver quality services and to improve efficiencies (Ramseook-Munhurrun, et al., 2010: 37). Actually, quality delivery of public services is not a privilege in a democratic society, as it is a legitimate expectation; is that the fundamental role of governments all over the world should be providing essential goods and services for the benefit of citizens regardless of the profit. Traditionally, public services in developing countries are described as non-productive and a drain on the wealth-producing part of the economy (Ali \& Yaseen: 2). This could be explained by the enormous challenges facing public sectors in these countries, such as political instability, politicians interference, excessive bureaucracies, corruption, and unattractive working conditions.

On the other hand, researchers have attempted to make distinctions between service quality and customer satisfaction, even if the two terms are always used interchangeably in practice (Kumasey, 2014: 174). Various studies that focused on a link between quality and satisfaction have argued for different views in terms of relationship (Daniel \& Berinyuy, 2010: 11). Moreover, few studies have been conducted on the relationship between customer satisfaction and service quality by testing and examining the service quality dimensions on both of them (Agbor, 2011: 4).

Thereby, the purpose of this study is to increase our knowledge and understanding of the relationship and differences between quality and satisfaction, by providing a framework for analyzing the aspects which lead to customer satisfaction in terms of service quality, and then distinguishing customers' expectations about public services from their perceptions (perceived quality) regarding the five dimensions of the SERVQUAL instrument (tangibility, reliability, responsiveness, assurance, and empathy). Furthermore, the low quality of public services in general, and thus the need for major public sector reforms in Egypt has been a serious issue on the national agenda for a long time. Nowadays, there are many complaints filed by the public due to delays in actions and services by some Egyptian public institutions. In this respect, the current research tries to measure the perceived quality of services offered by EgyptAir; an important public service agency, from the customers' perspective, then to study its relationship with customer satisfaction at this agency, and finally to propose some administrative and managerial reforms in order to promote service quality and satisfaction in this regard.

Therefore, this paper investigates a main research question which is:

"What is the nature of the relationship between service quality and customer satisfaction in the public sector? \& to what extent do service quality dimensions contribute to customer satisfaction at EgyptAir, in particular?" 
To answer this major question, the paper intends to find answers to the following questions:

- What is the meaning of service quality? \& what are the major determinants that influence perceived quality in general?

- What does the concept of customer satisfaction mean, in light of quality literature?

- What are the different views and various arguments concerning the relationship between service quality and customer satisfaction?

- How does perceived quality influence customer satisfaction in public services?

- Is there any meaningful difference between customers' expectations and their perceptions of the services provided by EgyptAir? \& how could service quality dimensions be used for enhancing customer satisfaction there?

\section{Research Importance:}

The importance of customers in business has made it vital to conduct continuous research about them. There has often been a need for customer research before (expectations), during (perceptions), and after sales (gaps) because of changes that may occur in the business process. During the past several decades with the increased competition, service quality has been a spotlight to be focused on by academics and practitioners, and it has been acknowledged as an observant competitive advantage and a supportive determinant of satisfying relationship with customers. In spite of this, there are still problems in defining and measuring service quality with no overall consensus emerging on either (El-Saghier \& Nathan, 2013: 2). On the other hand, researchers have usually paid great attention to the study of satisfaction as well. It can be said that it is a subjective concept, as it can be drawn from a variety of definitions found in literature (Yuktanandana \& Prasertsakul: 814).

The statistics show that little research was conducted on the relationship between customer satisfaction and service quality alone, and very little research on the relationship between customer satisfaction and service quality with respect to service quality dimensions, which indicates that there is still a need for more research in this area (Agbor, 2011: 4), putting into consideration the opposing results revealed by literature concerning this relation and the distinct methodology adopted here (systems approach). However, although some work has gone into identifying service quality and customer satisfaction in the public sector, it does not match the scale or volume of the work done in the private sector, hence another vacancy in literature has appeared. For that reason, this study was undertaken, as it seeks to reach better understanding of customers' expectations and perceptions of service quality, and to rank its dimensions within a major Egyptian public service organization; EgyptAir in which both the public and private traits meet together - as it will be explained later - and also to study whether those customers are satisfied with the offered services or not.

Thus, this study contributes to the existing body of knowledge by expanding or adding value to the relationships that are involved in customer satisfaction, service quality, and SERVQUAL dimensions, using an open system approach. In addition, it is of interest to academics investigating the applicability and reliability of service quality assessment tools, especially in the public sector. Moreover, this topic is of utmost importance for managers and the vast majority of service companies faced with the need to offer quality of service in its main dimensions and to satisfy their customers. So, the results of this research can be useful also to public service managers concerning how to deal with customers in order to assess and improve service delivery and design, and thereby maintain the organization's basic objectives and plans. Eventually, this 
paper is considered an attempt in the direction of developing comprehensive research to evaluate service delivery reforms adopted by public organizations in Egypt.

\section{Research Objectives:}

Since customer is the prime concern of the business service sectors of today, so researchers always conduct research about this customer, particularly what relates to his/her satisfaction. Furthermore, because satisfaction varies among individuals, companies, services, and even sectors, there is a need for ongoing research in this area (Agbor, 2011: 2).

In this paper, the concepts of customer satisfaction and service quality are elaborated. The research addresses and explains the correlation between service quality and customer satisfaction regarding the five main SERVQUAL dimensions. As well as, suggesting how public service sectors, especially in Egypt, can benefit from the endeavors of measuring and promoting service delivery for better customer satisfaction.

In this regard, the main objectives of this study are as follows:

- Exploring and defining the concept of service quality and distinguishing its various standards/ measures/ dimensions.

- Clarifying the several meanings of customer satisfaction in literature.

- Shedding light on the relationship between service quality and customer satisfaction according to the different opposite views.

- Examining the relationship between service quality dimensions and customer satisfaction in the public sector.

- Evaluating the perceived quality of services offered by EgyptAir from the customers' perspective, then providing insights to its managers and other similar state-owned service agencies, whether in Egypt or in other developing countries, in enhancing the influence of quality on satisfaction generally.

\section{Conceptual Framework:}

The model of analysis developed here is mainly to explain how quality relates to satisfaction, and to examine how this relationship takes place in public services, and hence guiding the empirical study. The relationship between quality and satisfaction could be understood through a clarification of how customers evaluate dimensions of quality, which leads to an overall evaluation of service satisfaction. Thus, the context of the research conceptual model, as outlined in figure (1) below, has placed a prominence in the role of service quality dimensions in boosting customer satisfaction in the public sector. Furthermore, it is important here while presenting the service delivery cycle to concentrate on the perceived quality, through identifying and measuring the gap between customers' expectations and perceptions for each dimension.

Even if service quality has several characteristic dimensions, this paper focuses only on the most evident ones, which are the five key predictors of the SERVQUAL tool developed by Parasuraman, et al. (1988). In agreement with (Daniel \& Berinyuy, 2010; Ramseook-Munhurrun, et al., 2010; Agbor, 2011; Archakova, 2013; El-Saghier \& Nathan, 2013; Martey \& Frempong, 2014; Ojo, et al., 2014; Selvakumar, 2015; Ali \& Yaseen), service quality is determined through; tangibility, reliability, responsiveness, assurance, and empathy. 
On the other hand, the overall customer satisfaction has been shown to be well-explained by satisfaction with service components (Ross \& Baldasare, 1998; Kumar \& Tsiros, 1999; Athanassopoulos \& Iliakopoulos, 2003). Therefore, the interest in perceived service quality in this study is because it has been proven to be the best determinant of customer satisfaction when it comes to service sectors.

Knowing that this research applies the SERVQUAL five dimensions on both service quality and customer satisfaction, as the paper adopts principally the customers' perspective of quality (perceived quality), which is very close or indicates their specifications or requirements of satisfaction. In sum, the researcher here believes that quality and satisfaction can be determined by the same attributes, and satisfaction is the customer's resulting sense from perceived service quality.

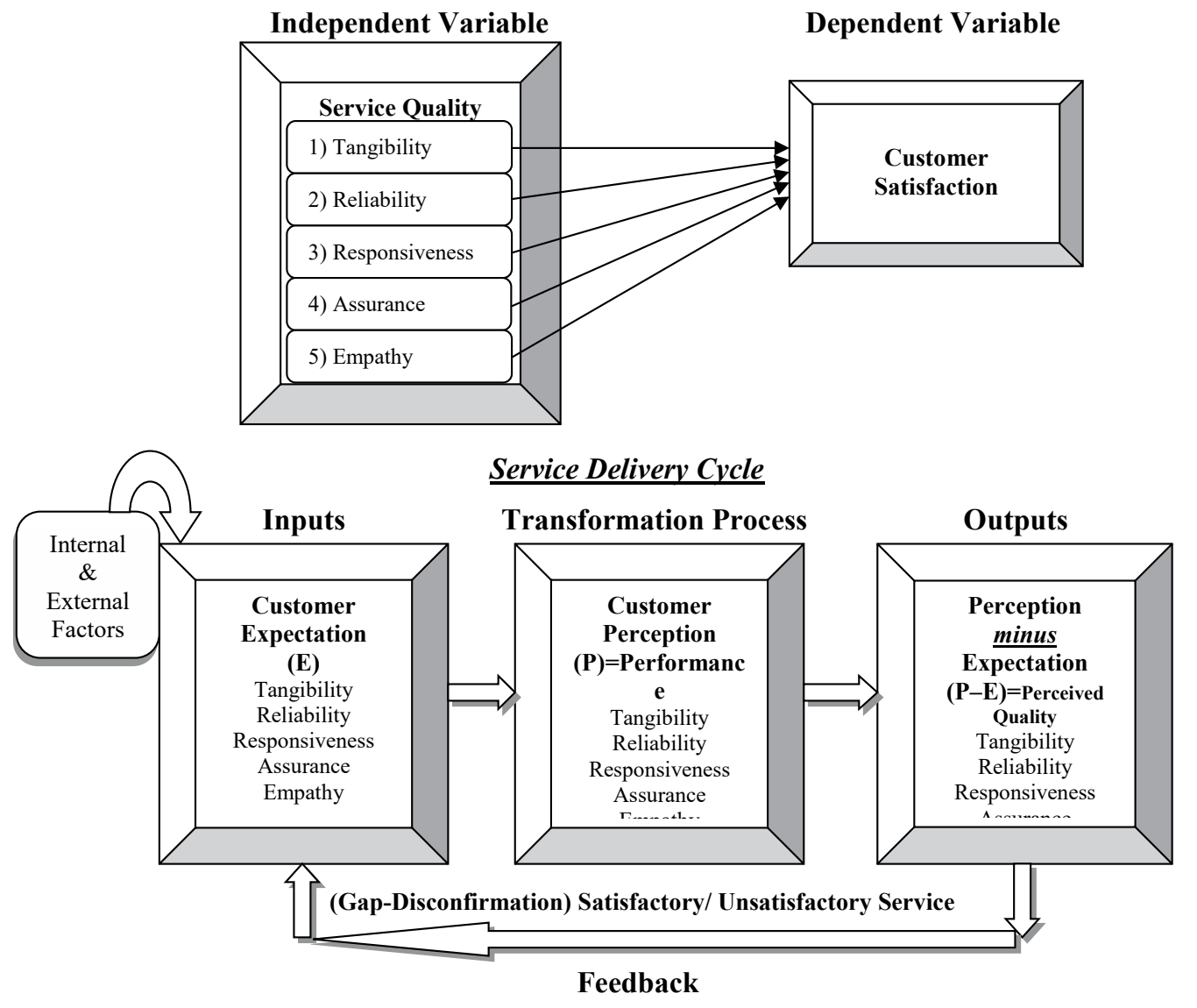

Source: Prepared by the Researcher.

Figure (1) Research Conceptual Model

\section{Research Methodology}

\section{1- Research Design}

The objective of this research is to clarify the relationship between service quality dimensions and customer satisfaction, especially in the public sector. The design of the study is both descriptive in the theoretical part and quantitative in the applied one. Theoretically, the researcher adopted the analytical approach 
to define the main concepts, and the systems approach to determine the relationship between variables as well, whilst she used an empirical study to investigate the correlations in practice.

Although the topic of this paper can be applied on a manufacturing sector and/or a service sector, it was limited here to the study of service sectors only, since service quality is best-evaluated in these sectors. Also, this topic concerns both employees/ or management and customers, but the research was interested in viewing this subject from the customers' perspective only.

Therefore, in addition to providing a brief overview of relevant literature, a field/ sample survey was used to capture customers' expectations of an excellent public service for each of the five dimensions of the SERVQUAL model, and then to compare these with their perceptions of the services delivered by a particular public service organization in Egypt, which is EgyptAir. This entity was determined as the case study here because it is considered one of the crucial public service institutions in Egypt that has launched many effective service development and improvement initiatives within the targeted dimensions during the past years. Moreover, it is a unique state-owned company rarely to be focused on by the academic studies of the Egyptian public service sector, as it has a special legislation permitting the management to operate without any interference from the government. Besides, the company is self-financing without any financial backing by the Egyptian government (EgyptAir Official Website, 17/3/2017). So, the researcher here aimed at examining this type of public service organizations to see whether it succeeded in eliminating or reducing some of the deficiencies of public services, caused by the overall intervention constraints and restrictions facing public sectors in general.

In order to accomplish the objectives of the empirical study, the research set out the following five hypotheses:

- H01: "There is no significant relationship at significance level $\alpha=0.05$ between tangibility and customer satisfaction with services provided by EgyptAir."

- H02: "There is no significant relationship at significance level $\alpha=0.05$ between reliability and customer satisfaction with services provided by EgyptAir."

- H03: "There is no significant relationship at significance level $\alpha=0.05$ between responsiveness and customer satisfaction with services provided by EgyptAir."

- H04: "There is no significant relationship at significance level $\alpha=0.05$ between assurance and customer satisfaction with services provided by EgyptAir."

- H05: "There is no significant relationship at significance level $\alpha=0.05$ between empathy and customer satisfaction with services provided by EgyptAir."

\section{2- Population, Sample, and Selection of the Sample:}

The field/ sample survey here was conducted during April 2017. The population was the customers of EgyptAir. Since the statistical population in this study was unlimited, thereby the following formula was used to get the ideal sample size:

$$
\mathrm{n}=\frac{\mathrm{Z}_{2 \alpha / 2} \delta_{2}}{\mathrm{E}^{2}}=\left(1.96^{*} 0.25\right) /(0.035)^{2}
$$

Accordingly, the sample size here was (400) person. Due to time and other resource constraints, this sample was selected using an online survey (online distribution through Google-forms tool). 


\section{3- Data Collection:}

Primary data was required to assess perceived quality and satisfaction with the service delivery at EgyptAir. For this purpose, a structured questionnaire was adopted as the data collection instrument in this research (the questionnaire was initially-prepared in English and then translated, since Arabic is the official language in Egypt).

The questionnaire used the SERVQUAL model developed by Parasuraman, et al. (1988), with some revision and modifications; is that its 22 original statements were merged (minimized) and rephrased (adjusted) to be relevant to the new context and to fit the research needs. In this regard, the questionnaire encompasses (34 items) and consists of the following sections; demographic profile of respondents (5 questions not included in the 34 main items), then customers' expectations (E) of excellent airlines (16 items) with respect to the five dimensions of (tangibility-reliability-responsiveness-assurance-empathy) ( 3 items for each + one item in which the customer is requested to arrange these dimensions according to their weight to him/her), eventually customers' perceptions ( $P$ ) about EgyptAir (18 items) regarding the previous five dimensions ( 3 items for each +3 items to assess the overall satisfaction).

The study utilized the questionnaire to collect the required primary data using a 5-point Likert scale as the measurement tool, ranging from $1=$ strongly disagree to $5=$ strongly agree; is that $2=$ disagree, $3=$ neutral, 4=agree, in order to measure the respondents' attitudes.

Knowing that prior to the actual distribution of questionnaires, a pre-test was conducted on (10) respondents to analyze the reliability and validity of the proposed questionnaire. Based on the comments and feedback of the pre-test and some management academic professors as well, amendments were made to the questionnaire for improvement.

\section{4- Reliability and Validity Test:}

For reliability of the variables, Cronbach's Alpha test was used to evaluate the stability of the questionnaire and reliability of the measures. Accordingly, Cronbach's Alpha was calculated for each variable in this research, as shown in table (1) below.

From the previous table, it is noticed that all

are above 0.70 , except tangibility which is still too close, so there is evidence that the variables of the study seem to be consistent, stable, reliable, and valid. This makes the following results can be taken into consideration.

Table (1)

Cronbach's Alpha Coefficients of the Research Variables

\begin{tabular}{cc}
\hline Cronbach's Alpha Coefficient $^{\left({ }^{* *}\right)}$ & Variable $^{(*)}$ \\
\hline 0.679 & Tangibility \\
\hline 0.701 & Reliability \\
\hline 0.718 & Responsiveness \\
\hline 0.778 & Assurance \\
\hline 0.720 & Empathy \\
\hline
\end{tabular}


$(*)$ Note that the dependent variable (Customer Satisfaction) is constructed from the independent variables' values, so that it is not found here.

(**) Note that an Alpha level of 0.70 or above is generally-considered to be acceptable.

\section{5- Methods of Statistical Analysis:}

Statistical Package for Social Survey (SPSS V.18) was the tool for compiling and processing data. Several statistical tools were employed for data analysis in the quantitative part of this research as follows:

- Descriptive Analysis: To describe data and indicators.

- Spearman Correlation Coefficient: To measure the correlation strength and direction between two ordinal variables. It usually takes values between (-1) and (1), in which the relation becomes stronger when the coefficient is near to any; (1) or (-1). While regarding the direction; if the coefficient is positive the relation will be extrusive and if it is negative the relation will be reverse.

- Simple Linear Regression: To test if there is a significant effect of one independent variable on the dependent variable and the level and direction of this effect. The effect is considered to be significant if $\mathrm{p}$-value is less than $5 \%$. Whilst the level is determined according to its value, and concerning the direction; if it is positive the relation will be extrusive and if it is negative the relation will be reverse.

\section{Literature Review: Concepts and Relationships}

\section{Service Quality:}

Quality is one of the major things that customers search for in an offer, which service happens to be one. Quality has long come to be recognized as a strategic mechanism for attaining operational efficiency and improving organizational performance (Amanfi Jnr., 2012: 21). Since the perceived quality of products is becoming the most important competitive factor in the business world today, thus the present business era is called "Quality Era". Consequently, service marketing authors have offered several allegories for this issue. For example, some name it as the most powerful competition weapon, and others consider it the organization's life-giving blood (Mosahab, et al., 2010: 72).

In general, a service could mean industry, performance, process, output, or offering, and it is defined differently in various service industries (Daniel \& Berinyuy, 2010: 8). An author identifies service as "any intangible act that one party offers to another and does not result in the ownership of anything" (Kotler \& Keller, 2009: 789). In all, the service can be defined as "an intangible offer by one party to another in exchange of money for pleasure" (Agbor, 2011: 8). The service has some main characteristics that distinguish it from a good which include; intangibility, heterogeneity, inseparability of production and consumption, and perishability. In fact, intangibility is the critical service-good distinction widely-cited by scholars, from which all other differences emerge. Intangibility means that services are not objects and they cannot be seen, heard, smelled, tasted, touched, or felt in the same way like goods can be (Yuktanandana \& Prasertsakul: $810-811)$.

As long as quality is a multi-dimensional phenomenon, so reaching service quality without determining the central aspects of quality is quite impossible. In this regard, quality can be defined as "the set of features and characteristics of a product or service that bear on its ability to satisfy stated or implied needs" 
(Kotler, et al., 2002: 831). In management context, the word quality can be used to refer to different things; accordance with specifications, accordance with requirements, excellence, adequacy of use, prevention of losses, or how to meet or to exceed customer expectations. The common point in most of these definitions is targeting of the customer (Fonseca, et al., 2010: 125).

Hence, service quality can be identified generally as "the overall evaluation of a service by the customer" (Eshghi, et al., 2008: 121). Therefore, service quality can intend to be the way in which customers are served in an organization that might be good or poor. Parasuraman, et al. (1988) have defined service quality as "the ability of the organization to meet or exceed customer expectation". It is the magnitude and direction of discrepancy between customers' expectations and perceptions in terms of different but relatively-important dimensions of service quality. Thus, perceived service quality results from comparisons of customers' expectations with their perceptions about services delivered by suppliers; if expectations are greater than perceptions, then service quality is less than satisfactory, vice versa (Ramseook-Munhurrun, et al., 2010: 38; Amanfi Jnr., 2012: 29). In this research, service quality is presented in the perspective of perceived quality because it is the most commonly-used in the services area.

Service quality is considered a complicated construct which has been the focus of a number of studies. In service marketing literature, service quality has been reported as a second-order construct composed of first-order variables. Various intellectuals have provided different conceptualizations over time. They include Lehtinen and Lehtinen's (1982) three-component conceptualization; interactive, physical, and corporate quality. Groonroos's (1984) three-component structure; technical, functional, and reputational quality. Garvin's (1988) nine-dimension approach; performance, features, conformance, reliability, durability, serviceability, response, aesthetics, and reputation. Hedvall and Paltschik's (1989) two-dimension model; willingness and ability to serve, as well as physical and psychological access. In addition to Oliver and Rust's (1994) functional, technical, and environmental quality construct (Amanfi Jnr., 2012: 26; Mosahab, et al., 2010: 72-73).

Furthermore, the Parasuraman, Zeithaml, and Berry's (1988) service quality five-dimension conceptualization, which eventually led to the development of the SERVQUAL instrument; the most widely-accepted and used model because of its universal applicability to a wide range of services. The original study by Parasuraman, et al. (1985) presented ten dimensions of service quality; reliability, responsiveness, competence, courtesy, credibility, security, tangibles, access, communication, and understanding the customer. Further investigation by Parasuraman, et al. (1988) led to exclude some of them. After refinement, these ten dimensions were reduced to five as below (Agbor, 2011: 8-10; Archakova, 2013: 9; Daniel \& Berinyuy, 2010: 41; Ramseook-Munhurrun, et al., 2010: 44; Ali \& Yaseen: 3; Selvakumar, 2015: 2-4; Ojo, et al., 2014: 143; El-Saghier \& Nathan, 2013: 3-5; Martey \& Frempong, 2014: 361-362):

1- Tangibility: This determinant is related to the availability of needed resources, appeal of physical facilities, equipment, and written communication material used by the organization, and also the appearance of personnel (employees and management team).

2- Reliability: This is the ability to perform the promised service accurately and dependably, which means the organization provides its customers with accurate service the first time without making any mistakes, and delivers what it has promised to do by the time that has been agreed upon. Accord- 
ing to Berry, et al. (1994); reliability is considered the vital core of service quality. Other dimensions will matter to customers if only a service is reliable (El-Saghier \& Nathan, 2013: 3).

3- Responsiveness: This is the readiness to help customers and provide prompt service, which means that employees of the organization are willing to provide the required service at any time without any inconvenience, and to respond to customers' requests and pay attention to their problems.

4- Assurance: This means the ability to inspire security, trust, and confidence, in addition to knowledgeable, professional management team, and good manners or courtesy of employees.

5- Empathy: This means caring and individual attention the organization provides its customers, understanding their needs, and performing in their best interests, as well as having convenient prices and operating hours.

Building on these five determinants, Parasuraman, et al. (1988) were able to develop a tool for assessing service quality by incorporating the gap analysis idea, which considers quality as the difference between customers' expectations and perceptions of the actual service delivered by providers (Ali \& Yaseen: 3). Zeithaml and Bitner (2000) suggested that customers' expectations are "beliefs about a service that serve as criteria against which service performance is judged". In other words, customers' expectations are seen as what they feel service provider should offer or how the service should be performed. Zeithaml, et al. (1990) identified four factors that influence expectations; personal needs, past experience, word-of-mouth, and external communications. While customers' perceptions of performance are "their experience of how the service is rendered" (Ramseook-Munhurrun, et al., 2010: 39; Daniel \& Berinyuy, 2010: 7). Service quality is thus operationalized as perception (P) minus expectation (E) or (P-E) (Amanfi Jnr., 2012: 30). If what is experienced is below expectation, perceived quality is low, whilst if what is experienced meets or exceeds expectation, then the customer perceives quality to be relatively-high.

Thereby, the SERVQUAL instrument is based on the "Gap Model"; in which better service quality results in a smaller gap. Specifically, five gaps organizations need to measure, reduce, and manage have been outlined in literature. These are attributed to the work of Zeithaml, et al. (1990), and they are explained by (Archakova, 2013: 10; Amanfi Jnr., 2012: 34-36) as follows:

1- Perception/ Customer Gap: It occurs due to the difference between customers' expectations and customers' perceptions, or between what customers expect and the service actually-provided in reality.

2- Understanding/ Knowledge Gap: It happens due to the difference between customers' expectations and management's perceptions, which means the inaccurate understanding of customers' expectations by managers.

3- Procedural/ Policy Gap: It occurs due to the difference between management's perceptions and service quality specifications, or the failure in translating management's perceptions into appropriate operating systems.

4- Behavioral/Delivery Gap: It happens due to the difference between service quality specifications and service delivery, or between specifications set by management and employees' performance.

5- Promotional/ Communication Gap: It occurs due to the difference between service delivery and external communication, which means the inability to fulfill promises and expectations created by advertising media and marketing. 
Actually, the last four gaps are identified as functions of the way in which the service is rendered, whereas the first gap is related directly to the customer, and as such it is considered to be the real measure of service quality from his/her perspective (perceived quality). In this research, the SERVQUAL methodology is used in measuring this gap particularly.

However, despite the array of challenges confronting the use of SERVQUAL, it is still a lasting and reliable scale as it remains the generic instrument for measuring service quality. This tool is applicable across an extensive spectrum of service sectors, although its format should be adapted to fit specific needs in order to assure valid results, and it would be most valuable when used to track service quality levels periodically. Many researchers have tried to use this tool in different service domains, such as professional services (e.g. Bojanic, 1991; Carman, 2000), medical services (e.g. Swartz \& Brown, 1989; Lam, 1997), tourism (e.g. Tribe \& Snaith, 1998; Atilgan, et al., 2003), airlines (e.g. Sultan \& Simpson, 2000; Park, et al., 2004), libraries (e.g. Nitecki, 1996; Coleman, et al., 1997), information systems (e.g. Kettinger \& Lee, 1994), banks and financial institutions (e.g. Angur, et al., 1993; Ravichandran, et al., 2010), restaurants and hotels (e.g. Min, et al., 2002), and government services (e.g. Donnelly, et al., 1995; Aidoo, et al., 2013). Besides, SERVQUAL has been applied in various countries, including India (e.g. Randheer, et al., 2011), China (e.g. Chung-Wei, et al., 2012), Nigeria (e.g. Ali, 2012), Ghana (e.g. Aidoo, et al., 2013), Egypt (e.g. El-Saghier \& Nathan, 2013), and the United States (e.g. Kilbourne, et al., 2004) (Mosahab, et al., 2010: 79; Ojo, et al., 2014: 143).

\section{Customer Satisfaction:}

Those who purchase products or services provided by companies are customers. In other words, a customer is "stakeholder of an organization who gives payment in exchange for the offer provided to him, with the purpose of fulfilling a need and maximizing satisfaction". Sometimes the terms customer and consumer are confusing. A customer can be a consumer, but a consumer may not necessarily be a customer (Agbor, 2011:6).

When a customer is happy with either the product or service delivered by a company, it is termed satisfaction. So, customer satisfaction is an appropriate phrase to describe "the attitudes and feelings that customers hold towards an organization/ product/ service". The measurement of customer satisfaction has emerged within the field of "Total Quality Management (TQM)", although it has been explored by several intellectuals from other scientific disciplines (e.g. marketing). The TQM school formalizes customer satisfaction as a quality component (Archakova, 2013: 17). Judging customer satisfaction could be very difficult at times because it is a trial to measure human feelings, thus the easiest way to know how customers feel and what they hope is to ask them.

In today's marketing era, organizations that successfully satisfy their customers enjoy higher retention levels and greater profitability due to increased customers' loyalty. This is why it is pivotal to keep customers satisfied (Daniel \& Berinyuy, 2010: 35). In fact, customer satisfaction is believed to be tightly-connected with comprehending customer behavior (Selvakumar, 2015: 2). In particular, customer satisfaction is a key element in the formation of customer desires for future buy. Furthermore, satisfied customers will possibly recommend and talk to others about their good experiences. In Jamal and Naser's (2002) opinion; this issue is more important, especially in the Middle Eastern cultures, where social life has been shaped in a way that interactions with others could enhance the society (Mosahab, et al., 2010: 73). 
In this regard, customer satisfaction can be defined in two basic ways; either as an outcome, or as a process. The first approach defines satisfaction as "an end state or a final situation resulting from the purchase/ consumption experience". The second approach emphasizes "the psychological, perceptual, and evaluative process that leads to satisfaction". Although diverse approaches of defining customer satisfaction are found in literature, the most popular of them is based on the fulfillment of customers' expectations (Archakova, 2013: 15). As Oliver (1977), Churchhill and Surprenant (1982), Tse and Wilton (1988), Yi (1990), Gerson (1993), Hill (1996), and Vavra (1997) have mentioned; satisfaction is "a standard of how the offered product or service fulfills customer expectation".

Also, (Wang \& Shieh, 2006: 197) have argued that customer satisfaction could be considered "a comparative behavior between inputs beforehand and post obtainments". In other words, customer satisfaction measures how well the organization's products and services meet or exceed the customer's expectations. These expectations often reflect many aspects of the company's activities, including its products and services, facilities, physical environment, staff...etc. (Kotler \& Keller, 2009: 789) as well, have further defined customer satisfaction as "a person's feelings of pleasure or disappointment resulting from contrasting a product or service perceived performance in relation to his/her expectations". If, for example, expectations are greater than performance, then the service is less than satisfactory (poor), and hence customer dissatisfaction occurs, vice versa. More specifically, the closer the gap between the expectation of the customer and the actual performance of the product or service, the higher the level of customer satisfaction (Yuktanandana \& Prasertsakul: 814).

Thereby, customer satisfaction literature employs the same $(E)$ and $(P)$ measurement methodology, as in service quality, and refers to it as the "Disconfirmation Theory", though the two constructs - customer satisfaction and service quality - are conceptually-different (Amanfi Jnr., 2012: 30). Disconfirmation is defined as "the customers' subjective assessments resulting from comparing their expectations and their perceptions of performance received". The disconfirmation theory states that satisfaction is influenced by the intensity (strength) and direction (positive or negative) of the gap (disconfirmation) between expectations and perceived performance. Expectations disconfirmation occurs in three forms (Amanfi Jnr., 2012: 39-40):

1- Positive Disconfirmation: It happens when perceived performance exceeds expectations (satisfaction).

2- Confirmation: It occurs when perceived performance meets (equals) expectations (neutral).

3- Negative Disconfirmation: It happens when perceived performance does not meet or is less than expectations (dissatisfaction).

In sum, satisfaction could be the state of being contented with a situation. As a matter of fact, satisfaction varies from one person to another; "one man's meal is another man's poison"; this highlights that it is sometimes very hard to satisfy everybody or to reach satisfaction among group of individuals (Agbor, 2011: 6). For this reason, (Giese \& Cote, 2002: 15) stated clearly that there is not a generic definition of customer satisfaction, and after conducting a study on various definitions they came up with the following one; customer satisfaction is identified by "a response that belongs to a particular focus and occurs at a certain time". Based on this, three general components can be clarified; (1) customer satisfaction is a cognitive or emotional reaction, (2) the reaction pertains to a particular focus, (3) it happens in a specific period.

From the former literature, it also seems that there is no overall consensus regarding the nature of this concept. Some authors argue that customer satisfaction results from a specific transaction that happens at 
a given time and by the benefits of the transaction (Oliver, 1980; Yi, 1990), while others see customer satisfaction in terms of cumulative satisfaction based on all experiences and contacts with the organization until a certain moment (Johnson \& Fornell, 1991; Fornell, 1992). Although this view is more comprehensive and useful in anticipating customer behavior and organizational performance, the nature of the service industry usually determines which of these two is more dominant (Amanfi Jnr., 2012: 37). Even in the case of the concept of dissatisfaction, contradictions amongst authors tend to arise. According to some researchers; satisfaction and dissatisfaction are two distinct concepts; that is the customer can be satisfied or dissatisfied in accordance with the level of quality received. However, for some other authors; the two concepts are not opposing but rather a continuum; is that some aspects tend to be causes of satisfaction and others are sources of dissatisfaction (Fonseca, et al., 2010: 126).

Finally, we have to confirm that providing outstanding service quality is not the only way to satisfy customers. For example, the National Business Research Institute (NBRI) suggested possible dimensions of customer satisfaction, including quality of service, speed of service, innocently, pricing, complaints/ problems, trust in employees, closeness of the relationship with contacts in the firm, positioning in customers' minds, and other types of services needed (Agbor, 2011: 7). Also, Zeithaml and Bitner (2001) argued that satisfaction is determined by the perception of service/ product quality, price, situation, and personal factors. Matzler, et al. (2002) went a step forward to classify factors that may influence customer satisfaction into basic, performance, and excitement factors (Daniel \& Berinyuy, 2010: 36-37).

\section{Service Quality and Customer Satisfaction:}

Actually, the rising interest in customer satisfaction is closely-related to the quality revolution started in the early 1980s. TQM scholars have realized that improving the quality of products and services could not only depend on the internal metrics of organizations, but it had also to be combined with customer feedback (Archakova, 2013: 17). Hence, customer satisfaction and service quality are leading components in the system of external relations of any organization today, as they largely determine its competitiveness.

Sometimes the terms quality and satisfaction are used interchangeably, as if they are one evaluative construct. For example, lacobucci, et al. (1995) found no differences between quality and satisfaction for disconfirmation, keeping promises, customization, empathy, friendliness, or purchase intentions. In addition, the study of (Fonseca, et al., 2010: 128) concluded that the company, non-customers, and customers do not make a distinction between them. However, (El-Saghier \& Nathan, 2013: 3) stated that perceived quality has been identified as a form of attitude related but not equivalent to satisfaction. Therefore, several researchers were interested in the link between the two concepts and how they differ. For instance, Liljander and Strandvik (1993) said that experience is not needed for judging quality and a service could be evaluated on the basis of knowledge about its provider, whilst satisfaction is an inner state/view resulted from the customer's own experience with a service.

In this respect, we can find two opposing trends or schools of thought regarding the relationship between service quality and customer satisfaction (Salazar, et al., 2004; Ahmed, et al., 2010). The first school supported the view that customer satisfaction helps to develop perception of high service quality, which means that satisfaction leads to quality or satisfaction can be seen as an antecedent of quality; the global 
perception (e.g. Bitner, 1990; Bolton \& Drew, 1991; Beerli, 2004; Eboli \& Mazzulla, 2012). Contrarily, the other school argued that service quality is a reason of or the ancestor of customer satisfaction, which means that quality leads to satisfaction (e.g. Cronin \& Taylor, 1992; McDougall \& Levesque, 1996, 2000; Antreas \& Opoulos, 2003; Negi, 2009; Kassim \& Abdullah, 2010) (Amanfi Jnr., 2012: 43-44). These studies all ensured a relationship between quality and satisfaction, but according to Asubonteng, et al. (1996); there is no agreement on the exact type of relationship between the two constructs (Daniel \& Berinyuy, 2010: 12).

As well as, some researchers proposed that quality and satisfaction could be determined by the same attributes, like Parasurman, et al. (1988) who tried to relate customer satisfaction to service quality, since what SERVQUAL tool struggles to measure is the attitude. As a result, more careful analysis leads to the conclusion that service quality and customer satisfaction are not entirely-distinct, but closely-related concepts (Siddiqi, 2011). The relationship between quality and satisfaction subsists when satisfaction is guaranteed. The organization's ability to satisfy the needs of the customer must take into account the various dimensions of quality (Fonseca, et al., 2010: 128).

At the same time, although service quality and customer satisfaction are related concepts, they are not exactly the same. The most common explanation of the difference between the two is that service quality is based on long-term cognitive assessments of the organization's service delivery, while customer satisfaction is a short-term emotional reaction to a specific service transaction (e.g. Parasuraman, et al., 1985; Bitner, 1990; Bolton \& Drew, 1991; Cronin \& Taylor, 1992; Bitner \& Hubbert, 1993; Rust \& Oliver, 1994). In spite of this, customers must first experience the quality before they can be satisfied or dissatisfied with the outcome. Then, through following service encounters customers may judge the levels of satisfaction or dissatisfaction - the cumulative overall satisfaction that was mentioned before - and can use this information to update the whole evaluation of service quality (Kumasey, 2014: 173-174), which will form later on, along with the customer's needs and desires and other external factors, his/her future quality expectations that will be compared while experience to his/her perceptions in this regard in order to determine the satisfaction or dissatisfaction level again, as if it is a cycle. Sureshchandar, et al. (2002) showed that, and confirmed the two-way/ dual relation between service quality and satisfaction (Mosahab, et al., 2010: 73). Putting into consideration that tracing the impact of cumulative satisfaction on long-term quality in practice and over time at all points of contact with the organization, needs a lot of time and expenses. So, the researcher here preferred not to study the mutual effect between quality and satisfaction, but to focus only on one side of this relationship which is the influence of the overall service quality on customer satisfaction at a certain time.

In sum, the causal relationship between service quality and customer satisfaction has been verified by research in several service sectors. It has been proven that service quality is positively-related to customer satisfaction (e.g. Baker-Prewitt, 2000; Kuo, 2003; Beerli, et al., 2004; Kotler \& Keller, 2009; Gera, 2011). Impressive/ surprising service quality may lead to high satisfaction of a customer. In contrast, poor/ low service quality may influence a customer to feel dissatisfied resulting in negative impacts on the company (Yuktanandana \& Prasertsakul: 816). Moreover, in relating service quality and customer satisfaction, researchers have been more precise about their measurement. The SERVQUAL model has been evidenced to be the best means to measure service quality in service sectors, especially from the customer perspective. This idea generates a presumption that the five dimensions of this model could have a direct relationship with customer satisfaction (Agbor, 2011: 15). 
On the other hand, the delivery of high standards of service quality by airline companies became a marketing requisite in the early 1990s, as the competition pressures increased (Baker, 2013: 68). Empirical studies of airline services show that service quality is central to the choice of airlines. According to Butler and Keller (1992); only the customer can truly define service quality in this industry. So, airlines adopt various quality strategies to achieve customer satisfaction. Customer satisfaction exists when the airline can provide passengers with privileges or benefits that exceed their expectations, and this is seen as "value-added". In this context, SERVQUAL has been proposed as a valid and reliable method in airline service quality research (e.g. Sultan \& Simpson, 2000; Gilbert \& Wong, 2003; Park, et al., 2004; Martey \& Frempong, 2014). In addition to SERVQUAL-relevant studies, many scholars measured airline service quality through multiple standards. For example, Gourdin (1988) categorized airline service quality in terms of timeliness, safety, and price. Truitt and Haynes (1994) used the check-in process, processing of luggage, timeliness, seat comfort, food and beverage quality, convenience of transit, and handling of customer problems as the criteria of service quality. Bowen and Headley (2000) indicated on-time arrival, denied boarding, mishandled baggage, airline safety, and passenger complaints on some items, such as reservation, refunds, fares, customer service, advertising, and frequent flyer programs. Besides, Bari, et al. (2001) came up with the AIRQUAL scale which has five major dimensions; airline tangibles, terminal tangibles, personnel, empathy, and image (Alotaibi, 2015: 39). Hence, it is seen that quality aspects used in evaluating airline services vary, but in general they can be classified within the SERVQUAL determinants (Pakdil \& Aydin, 2007: 229-230).

\section{Service Quality Dimensions and Customer Satisfaction in the Public Sector:}

Service industry plays an indispensable role in the economy of any state. Both the private and public sectors play significant roles in this industry. Actually, today's knowledge-intensive service businesses require reliable methods of quality assessment and improvement; is that service quality has become ever more important in promoting customer satisfaction. Public sectors, particularly, have come under a rising pressure to provide quality services and to enhance efficiency (Kumasey, 2014: 172). It is obvious that the role of public sectors in the delivery of quality services is even more crucial in developing countries. Customers' expectations and their quality specifications change when it comes to governmental services. At the same time, it should be noted that service quality in many public sector organizations is likely to be unsatisfactory. As the public sector is inherently-constrained/ restricted in the delivery of quality services and this is further made worse by structures, systems, and processes (Amanfi Jnr., 2012: 24-25), which may impose critical difficulties whether in measuring outcomes, or the greater scrutiny from the public and press, or the lack of freedom to act in an arbitrary fashion, in addition to the need for decisions based on law (Kumasey, 2014: 172).

According to Gowan, et al. (2001); service provision is more complex in the public sector because it is not simply a case of meeting expressed needs, but finding out unexpressed needs, setting priorities, allocating resources, and publicly justifying and accounting for what has been made. Furthermore, Caron and Giauque (2006) pointed out that public sector officials are currently-confronted with new professional challenges arising from the introduction of new principles and tools inspired by the shift towards "New Public Management (NPM)" (Ramseook-Munhurrun, et al., 2010: 40-41).

Knowing that service quality in the public sector is a theme which has been presented in many studies in various countries. Several researchers have dealt with service quality in public services (e.g. Anderson, 
1995; Rowley, 1998; Wisniewski, 2001; Donnelly, et al., 2006; Fonseca, et al., 2010; Amanfi Jnr., 2012; Ojo, et al., 2014; Adhikari \& Paul, 2015). It is observed that most of the prior research has concentrated on service quality in the American and European public service sectors, while some more recent research has focused on service quality in developing countries (Agus, et al., 2007). In this respect, Brysland and Curry (2001) stated that literature visibly supports the use of the SERVQUAL instrument in public sectors. Many studies have applied SERVQUAL for the evaluation of public services (e.g. Wisniewski \& Donelly, 1996; Sharifuddin, 1998/1999; Brysland \& Curry, 2001; Agus, et al., 2007; Ilhamie, 2010) (Ali \& Yaseen: 2-3). For that reason, the current research has utilized this model because it takes into account both customers' expectations and perceptions of services, which is considered in general the most systematic method to assess service quality in public service sectors from the customer perspective.

However, few studies have tested the service quality dimensions directly in the public sector to determine their impact on customer satisfaction. For example, Wisniewski (2001) carried out a study to measure customer satisfaction within the public sector across a range of Scottish Councils' services, by using the SERVQUAL model. In the library service, the analysis revealed that tangibles and reliability had negative gaps, whereas responsiveness and assurance had positive ones (Ramseook-Munhurrun, et al., 2010: 40-41).

Also, Amanfi Jnr. (2012) assessed the relationship between service quality dimensions and customer satisfaction at the Commission on Human Rights and Administrative Justice (CHRAJ) in Ghana. The results indicated that tangibility and reliability were not significantly-related to customer satisfaction, whilst responsiveness, assurance, and empathy were found to be significantly-related. As well as, Adhikari and Paul (2015) examined the effect of perceived service quality on satisfaction of customers in the branches of public sector banks in Silchar town of Assam, India. The study concluded that all the five dimensions of the SERVQUAL tool influenced significantly customer satisfaction, except the empathy dimension.

In spite of all the previous efforts that involved different countries, whether developed or developing ones, there is still a substantial need to analyze the direct relationship between each of the service quality dimensions and customer satisfaction in the Arab world, particularly in the Egyptian public sector, which is the aim of this research. In light of the unique state of EgyptAir in management and financing, the research will examine the effectiveness of this model in which public and private traits meet together, in addressing the total government intervention constraints and restrictions over public services in Egypt. In other words, testing whether the relatively-positive practices reported in the private sector generally are replicated at this company or not.

\section{Application: Empirical Study}

A field/ sample survey was used to identify how customers' satisfaction can be measured in relative to quality services provided by EgyptAir, using the SERVQUAL methodology. In this regard, perceived service quality is obtained by subtracting the expectation score from the perception score for each dimension of quality $(Q=P-E)$. Therefore, if perception exceeds expectation $(P>E)$, service quality in this dimension is very satisfactory (surprising/ high) for the customer. If perception equals expectation ( $P=E$ ), service quality is satisfactory (neutral/ moderate). However, if expectation exceeds perception ( $E>P$ ), service quality is unsatisfactory (unacceptable/ low). 


\section{About EgyptAir (Background):}

EgyptAir is one of the world's pioneer airlines. It was established in 1932 and became the seventh carrier in the world. EgyptAir is the flag carrier airline of Egypt. It is a state-owned company, 100\% owned by the government of Egypt. The EgyptAir Holding Company was created in 2002 with seven companies (two further companies were added later). This major airline corporate re-engineering in 2002 coincided with the establishment of the Egyptian Ministry of Civil Aviation and the government's ambitious strategy to modernize its airports and airline. The airline was given the right to operate without any interference from the government and the duty to do so without any financial backing. The airline is working to regain profitable operations following the revolution of 2011 (EgyptAir Official Website, 17/3/2017).

The airline is based at Cairo International Airport; its main hub, serving more than 80 destinations in the Middle East, Africa, Asia, Europe, and the Americas, with an extensive network of domestic services focused in Cairo. EgyptAir is a member of Star Alliance (since 2008), and also of Arabesk Airline Alliance and the Arab Air Carriers Organization. EgyptAir's mission is to create value for their customers, employees, owners, and stakeholders, and its vision is to deliver competitive customer service with true Egyptian spirit (EgyptAir Official Website, 17/3/2017).

\section{Sample Characteristics (Demographic Characteristics of Respondents):}

Table (2) provides some descriptive statistics of the sample to give a general view of the demographic characteristics of respondents.

Table (2)

Sample Description according to the Basic Characteristics of Respondents

\begin{tabular}{|c|c|c|c|c|c|c|c|c|c|c|c|c|}
\hline \multirow{2}{*}{$\begin{array}{c}\text { Variable } \\
\text { Faces }\end{array}$} & \multicolumn{2}{|c|}{ Gender } & \multicolumn{4}{|c|}{ Age } & \multicolumn{6}{|c|}{ Education } \\
\hline & Male & Female & $\begin{array}{l}\text { Under } \\
20 \text { years }\end{array}$ & \begin{tabular}{|l|l|}
$20-35$ \\
s years
\end{tabular} & $\begin{array}{l}6-50 \\
\text { years }\end{array}$ & $\begin{array}{c}\text { Over } 50 \\
\text { years }\end{array}$ & & Iool U & Jniver-sity & $\begin{array}{l}\text { Post } \\
\text { grad. }\end{array}$ & Other & Total \\
\hline Number & 164 & 236 & 4 & 127 & 150 & 119 & 4 & 0 & 206 & 150 & 4 & 400 \\
\hline Percentage & $41 \%$ & $59 \%$ & $1 \%$ & $31.8 \%$ & $37.5 \%$ & $29.7 \%$ & 10 & $\%$ & $51.5 \%$ & $37.5 \%$ & $1 \%$ & $100 \%$ \\
\hline Variable & \multicolumn{6}{|c|}{ Average use of airline services } & & \multicolumn{5}{|c|}{ Previous flights with EgyptAir } \\
\hline Faces & $\begin{array}{r}\text { Less } \\
\text { mo }\end{array}$ & $\begin{array}{l}\text { than } \\
\text { onth }\end{array}$ & $\begin{array}{l}\text { Every } \\
\text { month }\end{array}$ & $\begin{array}{l}\text { Every } 6 \\
\text { months }\end{array}$ & $\begin{array}{l}\text { Every } \\
\text { year }\end{array}$ & $\begin{array}{l}\text { More } \mathrm{t} \\
\text { one ye }\end{array}$ & & Once & \begin{tabular}{|c|}
$2-5$ \\
times \\
\end{tabular} & $\begin{array}{c}6-9 \\
\text { times }\end{array}$ & $\begin{array}{l}10 \text { times } \\
\text { or more }\end{array}$ & Total \\
\hline Number & & 0 & 12 & 124 & 131 & 133 & & 31 & 111 & 52 & 206 & 400 \\
\hline Percentage & & $\%$ & $3 \%$ & $31 \%$ & $32.8 \%$ & 33.29 & & $7.7 \%$ & $27.8 \%$ & $13 \%$ & $51.5 \%$ & $100 \%$ \\
\hline
\end{tabular}

The previous table indicates that $59 \%$ of the sample are females, $37.5 \%$ are between $36-50$ years, and $51.5 \%$ are university graduates. Also, $33.2 \%$ their average use of airline services is more than one year, and $51.5 \%$ their previous flights with EgyptAir are 10 times or more.

\section{Building Indicators of the Research Variables:}

It is important to mention that we already have five independent variables which are the SERVQUAL dimensions of tangibility, reliability, responsiveness, assurance, and empathy, and only one dependent variable which is customer satisfaction. 
Knowing that the independent variables were calculated as follows:

1- Sub-indicator of expectation for each independent variable built through getting average of the questions that measure this variable in the expectation's section.

2- Sub-indicator of perception for each independent variable built through the same previous method as expectation.

3- Final indicator for each independent variable calculated via obtaining the difference between its perception and expectation (Gap Score).

4- Whole service quality indicator built through getting average of the five independent variables, after recoding each of them in three categories (low - neutral - high) (Average Gap Score).

Whilst the dependent variable was calculated via summing all independent variables before recoding and then recoding them in 3 categories as mentioned later (unsatisfied - satisfied - highly-satisfied).

Table (3) below describes the sub-indicators in case of expectation and perception and the gap score for each independent variable.

Table (3)

Sub-Indicators and Gap Score for each Independent Variable

\begin{tabular}{ccccc}
\hline Independent Variable & Minimum & Maximum & Mean & Std. Deviation \\
\hline Tangibility (E) & 1.33 & 5.00 & 4.2340 & 0.78817 \\
\hline Tangibility (P) & 1.00 & 5.00 & 3.1616 & 0.75143 \\
\hline Tangibility (Gap) & $-3.33-$ & 1.00 & $-1.0724-$ & 1.00628 \\
\hline Reliability (E) & 1.00 & 5.00 & 4.2222 & 0.87001 \\
\hline Reliability (P) & 1.00 & 5.00 & 3.0619 & 0.77129 \\
\hline Reliability (Gap) & $-3.00-$ & 1.00 & $-1.1603-$ & 1.06562 \\
\hline Responsiveness (E) & 2.00 & 5.00 & 4.2160 & 0.81465 \\
\hline Responsiveness (P) & 1.00 & 5.00 & 3.2801 & 0.74653 \\
\hline Responsiveness (Gap) & $-3.33-$ & 1.00 & $-0.9359-$ & 1.03006 \\
\hline Assurance (E) & 1.67 & 5.00 & 4.2721 & 0.78714 \\
\hline Assurance (P) & 1.00 & 5.00 & 3.2877 & 0.82382 \\
\hline Assurance (Gap) & $-3.67-$ & 1.00 & $-0.9844-$ & 0.95719 \\
\hline Empathy (E) & 1.00 & 5.00 & 4.0238 & 0.85568 \\
\hline Empathy (P) & 1.00 & 5.00 & 3.1649 & 0.71084 \\
\hline Empathy (Gap) & $-3.33-$ & 2.00 & $-0.8589-$ & 0.97485 \\
\hline
\end{tabular}

From the table above, service quality gap of $(-1.07)$ was recorded for tangibility. This is because the perception mean value of 3.16 was less than the expectation mean value of 4.23 . In other words, perception was less than expectation in respect to tangibility. Customers' expectations regarding tangibility were not met. This could be that customers were not impressed with the level and quality of EgyptAir's physical facilities and equipment. It could also be the case that customers expected the staff to be more elegantly-dressed than they found.

A negative service quality gap was also recorded for reliability. A service quality gap of $(-1.16)$ means that customers' expectations regarding this dimension were not met or perception fell short of expectation. In other words, customers were dissatisfied with service quality at EgyptAir as far as reliability was con- 
cerned. This could be because promised deadlines were missed or that some defects were associated with many of the delivered services.

In the case of responsiveness, the service quality gap was $(-0.94)$, which means that perceptions here also did not exceed expectations. In other words, service quality was not satisfactory regarding responsiveness, thus customers found EgyptAir to be not responsive the way they expected. This could be explained by the fact that services were not promptly-delivered or complaints/ problems were not expeditiously-dealt with at EgyptAir.

With regards to the assurance dimension, quality gap was (-0.98). This indicates that customers' expectations here exceeded their perceptions of the actual service rendered. Service quality was therefore less than satisfactory. This might be because customers did not feel comfortable and safe with EgyptAir or maybe they did not find the staff having enough competence and expertise.

Eventually, a gap value of (-0.86) was recorded for the empathy dimension at EgyptAir, which means also perceptions did not exceed customers' expectations. This might be because customers did not get from EgyptAir the care and individual attention they need.

Hence, we can conclude from the previous data that the most unmet dimension at EgyptAir was reliability and the least was empathy. Knowing that assurance had the highest expectation mean value of 4.27 and the highest perception mean value of 3.29, while empathy had the least expectation mean value of 4.02 and reliability had the least perception mean value of 3.06 .

The following tables (4) and (5) represent the frequency and percentage of the different faces for the whole service quality indicator and the constructed variable of customer satisfaction.

Table (4)

Frequency and Percentage of Different Faces for Whole Service Quality

\begin{tabular}{|c|c|c|c|c|c|}
\hline Whole Service & & $\begin{array}{c}\text { Low } \\
\text { (Unsatisfactory) }\end{array}$ & $\begin{array}{c}\text { Neutral } \\
\text { (Satisfactory) }\end{array}$ & $\begin{array}{c}\text { High } \\
\text { (Surprising) }\end{array}$ & Total \\
\hline \multirow[t]{2}{*}{ Quality } & Frequency & 202 & 104 & 94 & 400 \\
\hline & Percentage & $50.5 \%$ & $26 \%$ & $23.5 \%$ & $100 \%$ \\
\hline
\end{tabular}

Table (5)

Frequency and Percentage of Different Faces for Customer Satisfaction

\begin{tabular}{c|ccccc}
\hline \multirow{2}{*}{$\begin{array}{c}\text { Customer } \\
\text { Satisfaction }\end{array}$} & Frequency & Unsatisfied & Satisfied & Highly-Satisfied & Total \\
\cline { 2 - 5 } & Percentage & 335 & 22 & 43 & 400 \\
\hline
\end{tabular}

From the previous tables, it is clear that most of the sample believe that service quality at EgyptAir is low $(50.5 \%)$ or moderate $(26 \%)$. At the same time, the majority of around $84 \%$ of the sample are not satisfied with the services offered by EgyptAir, and this supports the results discussed before for each independent variable.

Finally, table (6) below clarifies the importance of SERVQUAL dimensions in the airline industry generally, according to the respondents' answers of question 16. However, table (7) shows the frequency and percentage of the different faces of Likert scale for the last 3 questions about the overall satisfaction of customers with EgyptAir's services.

The table (6) presents the frequency and valid percentage of all ranks. We find that the most important feature in the airline industry from the respondents' point of view is reliability (highest rank $1=41 \%$ ), whereas 
the least important factor is empathy (lowest rank $5=26.3 \%$ ), which is completely the opposite with what found at EgyptAir as mentioned before; is that the most unmet dimension there is reliability and the least is empathy.

Table (6)

Importance of SERVQUAL Dimensions in Airline Industry

\begin{tabular}{|c|c|c|c|c|c|c|c|}
\hline SERVQUAL Dimension & Rank & 1 & 2 & 3 & 4 & 5 & Total \\
\hline \multirow{2}{*}{$\begin{array}{l}\text { 1- The appearance of the airline's equipment, } \\
\text { communication materials, and personnel. } \\
\text { (Tangibility) }\end{array}$} & Frequency & 141 & 59 & 86 & 19 & 95 & 400 \\
\hline & $\begin{array}{c}\text { Valid } \\
\text { Percentage }\end{array}$ & $35.3 \%$ & $14.7 \%$ & $21.5 \%$ & $4.7 \%$ & $23.8 \%$ & $100 \%$ \\
\hline \multirow{2}{*}{$\begin{array}{l}\text { 2- The airline's ability to perform the promised } \\
\text { service dependably and accurately. (Reliability) }\end{array}$} & Frequency & 164 & 86 & 61 & 39 & 50 & 400 \\
\hline & $\begin{array}{c}\text { Valid } \\
\text { Percentage }\end{array}$ & $41 \%$ & $21.5 \%$ & $15.3 \%$ & $9.7 \%$ & $12.5 \%$ & $100 \%$ \\
\hline \multirow{2}{*}{$\begin{array}{l}\text { 3-The airline's willingness tohelpcustomers and } \\
\text { toprovidepromptservice.(Responsiveness) }\end{array}$} & Frequency & 106 & 108 & 83 & 70 & 33 & 400 \\
\hline & $\begin{array}{c}\text { Valid } \\
\text { Percentage } \\
\end{array}$ & $26.5 \%$ & $27 \%$ & $20.8 \%$ & $17.5 \%$ & $8.2 \%$ & $100 \%$ \\
\hline \multirow{2}{*}{$\begin{array}{l}\text { 4- The knowledge and courtesy of the airline's } \\
\text { employees and their ability to convey trust } \\
\text { and confidence. (Assurance) }\end{array}$} & Frequency & 97 & 72 & 103 & 86 & 42 & 400 \\
\hline & $\begin{array}{c}\text { Valid } \\
\text { Percentage }\end{array}$ & $24.2 \%$ & $18 \%$ & $25.8 \%$ & $21.5 \%$ & $10.5 \%$ & $100 \%$ \\
\hline \multirow{2}{*}{$\begin{array}{l}\text { 5- The caring and personal attention the } \\
\text { airline provides customers. (Empathy) }\end{array}$} & Frequency & 99 & 59 & 59 & 78 & 105 & 400 \\
\hline & $\begin{array}{l}\text { Valid } \\
\text { Percentage }\end{array}$ & $24.8 \%$ & $14.7 \%$ & $14.7 \%$ & $19.5 \%$ & $26.3 \%$ & $100 \%$ \\
\hline
\end{tabular}

Table (7)

Frequency and Percentage of Different Faces of Likert Scale for the Last 3 Questions about the Overall Satisfaction

\begin{tabular}{|c|c|c|c|c|c|c|c|}
\hline Question & & $\begin{array}{l}\text { Strongly } \\
\text { Disagree }\end{array}$ & Disagree & Neutral & Agree & $\begin{array}{c}\text { Strongly } \\
\text { Agree }\end{array}$ & Total \\
\hline \multirow{2}{*}{$\begin{array}{l}\text { 32- Generally, you are satisfied with the } \\
\text { services offered by EgyptAir. }\end{array}$} & Frequency & 27 & 78 & 120 & 152 & 23 & 400 \\
\hline & Percentage & $6.8 \%$ & $19.5 \%$ & $30 \%$ & $38 \%$ & $5.7 \%$ & $100 \%$ \\
\hline \multirow{2}{*}{$\begin{array}{l}\text { 33- You will continue to use EgyptAir in } \\
\text { the future. }\end{array}$} & Frequency & 23 & 63 & 114 & 133 & 67 & 400 \\
\hline & Percentage & $5.7 \%$ & $15.7 \%$ & $28.5 \%$ & $33.3 \%$ & $16.8 \%$ & $100 \%$ \\
\hline \multirow{2}{*}{$\begin{array}{l}\text { 34- You will recommend travelling with } \\
\text { EgyptAir to your friends and relatives. }\end{array}$} & Frequency & 35 & 82 & 116 & 108 & 59 & 400 \\
\hline & Percentage & $8.7 \%$ & $20.5 \%$ & $29 \%$ & $27 \%$ & $14.8 \%$ & $100 \%$ \\
\hline
\end{tabular}

From the previous table, it is clear that the highest responses in the sample for these three questions are either agree or neutral, which also contradicts with the preceding results based on gap scores. This could be explained by the fact that there are some other factors - other than service quality - that might play an essential role in the overall customers' satisfaction at EgyptAir in general.

\section{Testing the Research Hypotheses:}

- H01: "There is no significant relationship at significance level $\alpha=0.05$ between tangibility and customer satisfaction with services provided by EgyptAir."

- H02: "There is no significant relationship at significance level $\alpha=0.05$ between reliability and customer satisfaction with services provided by EgyptAir."

- H03: "There is no significant relationship at significance level $\alpha=0.05$ between responsiveness and customer satisfaction with services provided by EgyptAir." 
- H04: "There is no significant relationship at significance level $\alpha=0.05$ between assurance and customer satisfaction with services provided by EgyptAir."

- H05: "There is no significant relationship at significance level $\alpha=0.05$ between empathy and customer satisfaction with services provided by EgyptAir."

In order to test these hypotheses and to analyze the correlations between variables, Spearman correlation coefficient was used to determine the strength and direction of relations. The results are presented in table (8) below.

Table (8)

Correlations between SERVQUAL Dimensions and Customer Satisfaction

\begin{tabular}{|c|c|c|c|c|c|c|}
\hline \multicolumn{2}{|c|}{ SERVQUAL Dimension } & Tangibility & Reliability & Responsiveness & Assurance & Empathy \\
\hline Customer & Spearman Coefficient & 0.529 & 0.568 & 0.538 & 0.511 & 0.476 \\
\hline Satisfaction & P-Value & 0.000 & 0.000 & 0.000 & 0.000 & 0.000 \\
\hline
\end{tabular}

The table above indicates that there is a significant ( $p$-value is less than 0.05 ) positive and moderate ( $R$ is around 0.5 ) relationship at significance level $\alpha=0.05$ (with confidence level $95 \%$ ) between all of the SERVQUAL dimensions (tangibility, reliability, responsiveness, assurance, and empathy) and customer satisfaction with services offered by EgyptAir. That means the increase in any or all of the dimensions of service quality will increase customer satisfaction. Knowing that the highest correlated variable with customer satisfaction is reliability, as $\mathrm{R}=0.568$.

On the other hand, simple linear regression was also used to test the impact of SERVQUAL dimensions (tangibility, reliability, responsiveness, assurance, and empathy) on customer satisfaction. The results are presented in table (9).

\section{Table (9)}

Simple Linear Regression Models of the Dependent Variable on the Different Independent Variables

\begin{tabular}{|c|c|c|c|c|c|}
\hline $\begin{array}{c}\text { Simple Linear } \\
\text { Regression Model }\end{array}$ & $\begin{array}{c}\text { Dependent } \\
\text { Variable } \\
\end{array}$ & $\begin{array}{c}\text { Independent } \\
\text { Variable } \\
\end{array}$ & Beta & $\begin{array}{c}\text { Significance of } \\
\text { the Model } \\
\end{array}$ & $\begin{array}{c}\text { Adjusted R } \\
\text { Squared } \\
\end{array}$ \\
\hline Model 1 & \multirow{5}{*}{$\begin{array}{l}\text { Customer } \\
\text { Satisfaction }\end{array}$} & Tangibility & 0.722 & 0.000 & 0.689 \\
\hline Model 2 & & Reliability & 0.737 & 0.000 & 0.798 \\
\hline Model 3 & & Responsiveness & 0.775 & 0.000 & 0.806 \\
\hline Model 4 & & Assurance & 0.848 & 0.000 & 0.807 \\
\hline Model 5 & & Empathy & 0.789 & 0.000 & 0.759 \\
\hline
\end{tabular}

The previous table shows that:

- $\quad$ For the first model, when tangibility is the independent variable:

- Tangibility in general has a significant positive effect on customer satisfaction with services provided by EgyptAir at confidence level 95\%, and this appears from the value of beta.

- From adjusted $\mathrm{R}$ squared, it is noticed that tangibility has the ability to explain about $69 \%$ from the variation in customer satisfaction.

- $\quad$ For the second model, when reliability is the independent variable:

- Reliability in general has a significant positive effect on customer satisfaction with services provided by EgyptAir at confidence level 95\%.

- From adjusted $\mathrm{R}$ squared, it is noticed that reliability has the ability to explain about $80 \%$ from the variation in customer satisfaction. 
- For the third model, when responsiveness is the independent variable:

- Responsiveness in general has a significant positive effect on customer satisfaction with services provided by EgyptAir at confidence level 95\%.

- From adjusted $\mathrm{R}$ squared, it is noticed that responsiveness has the ability to explain about $81 \%$ from the variation in customer satisfaction.

- For the fourth model, when assurance is the independent variable:

- Assurance in general has a significant positive effect on customer satisfaction with services provided by EgyptAir at confidence level 95\%.

- From adjusted $\mathrm{R}$ squared, it is noticed that assurance has the ability to explain about $81 \%$ from the variation in customer satisfaction.

- For the fifth model, when empathy is the independent variable:

- Empathy in general has a significant positive effect on customer satisfaction with services provided by EgyptAir at confidence level 95\%.

- From adjusted $R$ squared, it is noticed that empathy has the ability to explain about $76 \%$ from the variation in customer satisfaction.

Therefore, we can say that developing and promoting the SERVQUAL five dimensions is a must, not only a need, in providing satisfactory services, as they are major determinants of customer satisfaction at EgyptAir.

In sum, the study accepts that there is a significant relationship at significance level $\alpha=0.05$ between all dimensions of service quality and customer satisfaction with services offered by EgyptAir. Thus, we can eventually conclude that the analysis here does not support (rejects) the five hypotheses in this research.

\section{Conclusion: Concluding Remarks}

In today's market of severe competition, service quality is recognized as the most vital aspect that contributes to the establishment and evolution of credibility and reputation of the organization in the minds of public. Furthermore, the satisfaction of customers becomes extremely-important for the survival and growth of organizations in this era. In this regard, service quality dimensions are considered substantial predictors for judging the satisfaction levels of customers. Actually, it is necessary that the company be aware of the quality dimensions that customers value most in order to tailor the service to their needs and desires, then maximizing profitability, customer satisfaction, retention, and loyalty.

This study offers several contributions to literature, as it expands on the existing knowledge by identifying service quality dimensions that may serve as points of departure to develop action plans for boosting perceived quality, and hence satisfaction with the services offered by public organizations (reducing service quality gaps); is that good quality is not based only on the service provider, but on the point of view/ opinion of customers alike (comparing perceptions to expectations). Thereby, the research aims to understand the main factors that affect customer satisfaction with regards to SERVQUAL dimensions, and then it proposes a model that would support decision makers to promote sustainable quality and to enhance customer (citizen) satisfaction, particularly in the Egyptian public service sector.

The field study here has some limitations that could be divided into two groups; selection of the case study and the process of data collection. EgyptAir was determined as the case study because it is considered a unique state-owned company operating without any interference from the Egyptian government, which 
may help to reduce some of the constraints facing public organizations. In addition, the decision about using an online survey in gathering data was taken considering time and cost limitations. Thus, the findings of this study need to be inferred with a little bit of caution while making any kind of generalization.

Through both the theoretical and applied parts of this research, it has reached the following results and recommendations:

\section{Results and Findings:}

Customers all over the world have become more quality-conscious, therefore customers' requirements for higher quality services have been grown. Public service sectors, especially, are obliged to provide excellent services to their customers to get sustainable competitive advantage. By realizing the gap between the expected and actual service delivery, customer satisfaction can be extremely-developed.

This study claims in general that service quality and its dimensions are positively-related with customer satisfaction in public organizations; is that when customers get what they expect and need they tend to feel satisfied with the service rendered than when they do not get what they want and expect. In this respect, the main findings here are:

- The paper highlights how important it is for any organization, whether a private or a public one, to consider the opinion of customers in identifying areas of service quality improvements which may generate satisfaction, specifically in light of the mutual/ dual/ two-way or cyclic relationship the study confirmed between both quality and satisfaction.

- The research indicates that the SERVQUAL tool appears to be a reliable scale to measure service quality in general, as well as it provides a useful diagnostic role in monitoring service quality in the context of the public sector in particular, although its format should be adapted to fit the different needs.

- The study confirms that highly-competitive market conditions in the airline industry pressurize private and public airlines to deliver high-quality services. At the same time, it is revealed that the airline industry, especially in developing countries, has been struggling with many challenges like; cutting costs, managing fluctuating demands, keeping up with tight quality specifications, while trying to satisfy the needs of various customer clusters. Thus, to offer high-quality services airlines should first understand customers' expectations and perceptions. Next, they must focus on how to deliver the most convenient service to satisfy them.

- Practical implications clarify that services at EgyptAir are not providing the level of quality demanded by customers, in spite of all reforms and developments, and despite the unique management style of EgyptAir as a state-owned company which failed somehow in averting public sectors' problems and restrictions. The empirical findings of this research prove that the overall service quality perceived by customers was not satisfactory, meaning that in all aspects/ dimensions - particularly reliability - customers' expectations were higher than (exceeded) their perceptions, and then there is a significant shortfall in meeting customer expectations because the quality of the rendered services is relatively-low. However, although the final output may not be satisfactory, it does not necessarily mean that customers are dissatisfied at all. In fact, there are some other factors which can play an essential role in customers' satisfaction, such as management and leadership, internal systems and policies, marketing (image/reputation), situational and personal factors...etc. Putting into consideration that customers using domestic airlines usually do so because of the price - al- 
ready included in the empathy dimension; the least unmet dimension at EgyptAir - and they often do not have a true service expectation package.

- The results of this analysis provide evidence that all dimensions of service quality - especially reliability - are significantly and positively-related to customer satisfaction at EgyptAir, thus service quality negative gaps must be reduced in all dimensions in order to enhance satisfaction. A remarkable step in minimizing these gaps is to measure customer expectations and communicate them to front-line employees. If front-line employees do not fully understand the needs of customers, they cannot be expected to meet or exceed these needs. Hence, maybe the service quality shortfalls at EgyptAir are related somehow to the inadequate internal systems to support front-line employees generally (behavioral gap and procedural gap).

\section{Recommendations and Future Research:}

With better understanding of customers' perceptions, public organizations can determine the required actions to meet customers' needs and expectations. They can identify their own strengths and weaknesses and where they stand in comparison to their competitors, and thereby chart out paths for future improvements in service quality that may eventually result in customer satisfaction. Accordingly, the study has made the following recommendations:

- Measurement of service quality should be a basic and cyclic procedure applied regularly in order to assure quality in public services. These evaluations should be taken seriously by the officials in public service organizations, particularly in developing countries, to gain and ensure a raise in the satisfaction and confidence of the public (tax-payers) towards public services.

- In order to bridge the gaps between customers' perceptions and expectations of service delivery in public sectors, especially in developing countries, public service organizations ought to offer more training to front-line employees to enhance their customer service skills and to develop their knowledge, so that they can provide a fast and reliable service to customers. In this regard, it is also necessary to upgrade all the physical aspects of public service premises into more modern sites with updated electronic infrastructure.

- The findings suggest that EgyptAir needs measures to reinforce all dimensions of service quality from the gap analysis carried out. Empirical results can guide management at EgyptAir to take corrective actions that lead to its progress, by identifying areas that have weaknesses in terms of satisfying customers' interests and needs. In addition, it is recommended that EgyptAir should invest more of its resources and concentrate on those service quality attributes in which customers considered most important - particularly reliability.

- Concerning future research; a similar study might be conducted with a broader sample includes respondents from various countries, so that results could be generalized to a larger population. This coupled with the necessity of considering the differences according to demographic data and some other aspects, like ticket class, flight destination, and purpose of travelling. Also, future research could be to identify the factors that influence the formation of customers' expectations. Besides, the study of service quality dimensions from the employees and/or management views is too valuable. As well as, there is a need to conduct further comprehensive research to examine those other determinants - apart of service quality - that might lead to satisfaction or dissatisfaction, specifically in multiple cultures. Finally, further research could be to test these key variables in manufacturing sectors. 


\section{References}

- Adhikari, Kingshuk and Biswajit Paul. (2015). "Perceived Service Quality and Customer Satisfaction in Public Sector Banks: An Empirical Study", Vidyasagar University Journal of Commerce, Vol. 20, pp. 151-159.

- Agbor, Jenet Manyi. (2011). “The Relationship between Customer Satisfaction and Service Quality: A Study of Three Service Sectors in Umea", Master's Thesis, Umea University: School of Business.

- $\quad$ Akhtar, Naeem; Adeel Ahmad; Hammad Ahmad; Wasim Abbas \& Tayyaba Noreen Abbas. (2016). "Impact of Service Quality on Customer Satisfaction: A Case of National Bank of Pakistan", International Review of Management and Business Research (IRMBR), Vol. 5, Issue 2, (June), pp. 536-546.

- Ali, Mona A. and Ehab A. Yaseen. (2016). Service Quality in Public Services: A Study in Urban Egypt, Available at https://www.pomsmeetings.org/confpapers/043/043-1653.pdf, 2/12/2016.

- Alotaibi, Mishal M. (2015). “Evaluation of "AIRQUAL" Scale for Measuring Airline Service Quality and Its Effect on Customer Satisfaction and Loyalty", PhD Thesis, Cranfield University: School of Aerospace, Transport and Manufacturing, Centre for Air Transport Management.

- Amanfi Jnr., Benjamin. (2012). "Service Quality and Customer Satisfaction in Public Sector Organizations: A Case Study of the Commission on Human Rights and Administrative Justice", Master's Thesis, Kwame Nkrumah University of Science and Technology: Institute of Distance Learning.

- Archakova, Asya. (2013). "Service Quality and Customer Satisfaction, Case Study: Company X", Thesis on Degree Programme in International Business, Saimaa University of Applied Sciences: Faculty of Business Administration Lappeenranta.

- Baker, David Mc. A. (2013). “Service Quality and Customer Satisfaction in the Airline Industry: A Comparison between Legacy Airlines and Low-Cost Airlines", American Journal of Tourism Research, Vol. 2, No. 1, pp. 67-77.

- Daniel, Chingang Nde \& Lukong Paul Berinyuy. (2010). “Using the SERVQUAL Model to Assess Service Quality and Customer Satisfaction: An Empirical Study of Grocery Stores in Umea", Master's Thesis, Umea School of Business.

- EgyptAir Official Website. (2017). Available at http://www.egyptair.com/en/Pages/default.aspx, $17 / 3 / 2017$

- El-Saghier, Niveen \& Demyana Nathan. (2013). “Service Quality Dimensions and Customers' Satisfactions of Banks in Egypt", The 20 $0^{\text {th }}$ International Business Research Conference, Dubai: (4-5 April).

- Eshghi, A., S. K. Roy and S. Ganguli. (2008). “Service Quality and Customer Satisfaction: An Empirical Investigation in Indian Mobile Telecommunications Services", Marketing Management Journal, Vol. 18, No. 2, pp. 119-144.

- Fonseca, Filipa, Sofia Pinto and Carlos Brito. (2010). "Service Quality and Customer Satisfaction in Public Transports", International Journal for Quality Research, Vol. 4, No. 2, pp. 125-130.

- Giese, J. L. and J. A. Cote. (2002). “Defining Consumer Satisfaction”, Academy of Marketing Science, Vol. 2000, No. 1, pp. 1-24. 
- Kotler, P.; G. Armstrong; J. Saunders and V. Wong. (2002). Principles of Marketing. $3^{\text {rd }}$ (ed.), Europe: Prentice Hall.

- $\quad$ Kotler, P. and K. L. Keller. (2009). Marketing Management. $13^{\text {th }}$ (ed.), New Jersey: Pearson Education Inc., Upper Saddle River.

- Kumasey, Anthony Sumnaya. (2014). "Service Quality and Customer Satisfaction: Empirical Evidence from the Ghanaian Public Service", European Journal of Business and Management, Vol. 6, No. 6, pp. 172-181.

- Martey, Edward Markwei and Joseph Frempong. (2014). “The Impact of Perceived Service Quality Dimensions on Customer Satisfaction in the Airline Industry in Ghana", International Journal of Research (IJR), Vol. 1, Issue 10, (November), pp. 359-374.

- Mosahab, Rahim; Osman Mahamad and T. Ramayah. (2010). “Service Quality, Customer Satisfaction and Loyalty: A Test of Mediation", International Business Research, Vol. 3, No. 4, (October), pp. 72-80.

- Ojo, Thomas Kolawole; Dickson Okoree Mireku; Suleman Dauda and Ricky Yao Nutsogbodo. (2014). "Service Quality and Customer Satisfaction of Public Transport on Cape Coast-Accra Route, Ghana", Developing Country Studies, Vol. 4, No. 18, pp. 142-149.

- Pakdil, Fatma and Ozlem Aydin. (2007). "Expectations and Perceptions in Airline Services: An Analysis Using Weighted SERVQUAL Scores", Journal of Air Transport Management, Vol. 13, pp. 229237.

- Parasuraman, A.; Valarie A. Zeithaml and Leonard L. Berry. (1988). "SERVQUAL: A Multiple-Item Scale for Measuring Consumer Perceptions of Service Quality", Journal of Retailing, Vol. 64, No. 1, (Spring), pp. 12-40.

- Ramseook-Munhurrun, Prabha; Soolakshna D. Lukea-Bhiwajee and Perunjodi Naidoo. (2010). "Service Quality in the Public Service", International Journal of Management and Marketing Research (IJMMR), Vol. 3, No. 1, pp. 37-50.

- Selvakumar, J. Joshua. (2015). “Impact of Service Quality on Customer Satisfaction in Public Sector and Private Sector Banks", Purushartha, Vol. VIII, No. 1, (Mar-Aug), pp. 1-12.

- Wang, I. M. and C. J. Shieh. (2006). “Relationship between Service Quality and Customer Satisfaction: The Example of CJCU Library", Journal of Information and Optimization Sciences, Vol. 27, No. 1, pp. 193-209.

- Wisniewski, Mik. (2001). “Using SERVQUAL to Assess Customer Satisfaction with Public Sector Services", Managing Service Quality, Vol. 11, No. 6, pp. 380-388.

- Yuktanandana, Ajdanai and Dissatat Prasertsakul. (2016). "The Effects of Service Quality and Customer Satisfaction on Customer Loyalty: A Case of Thai Mobile Network Industry", Interdisciplinary Management Research XI, pp. 808-823, Available at ftp://ftp.repec.org/opt/ReDIF/RePEc/ osi/journl/PDF/InterdisciplinaryManagementResearchXI/IMR11a59.pdf, 12/12/2016. 


\section{Questionnaire}

This questionnaire aims to study the relationship between quality dimensions and customer satisfaction with services provided by "EgyptAir".

\section{Kindly mark the most appropriate answer in front of each statement.}

\section{First / Demographic Data:}

- Gender:

male

female

- Age:

under 20 years

20-35 years

$36-50$ years

over 50 years

- Education: high school

university

postgraduate other

- $\quad$ Average use of airline services: less than month - every month - every 6 months - every year more than one year

- Previous flights with EgyptAir: once 2-5 times $\quad 6-9$ times 10 times or more

\section{Second/Customer Expectation:}

Directions: The following set of statements is related to the kind of public organizations that deliver excellent airline services. Please show the extent to which you think such service organizations (airlines) should possess the feature described by each statement. Your choice will truly reflect your expectations regarding these excellent airlines.

\begin{tabular}{|c|c|c|c|c|c|c|}
\hline Dimension & Statement & $\begin{array}{c}\text { Strongly } \\
\text { Agree }\end{array}$ & Agree & Neutral & Disagree & $\begin{array}{l}\text { Strongly } \\
\text { Disagree }\end{array}$ \\
\hline \multirow{3}{*}{ Tangibility } & $\begin{array}{l}\text { Excellent airlines should have up-to-date, well- } \\
\text { 1. maintained equipment and modern-looking, appropriate } \\
\text { physical facilities (including their offices, systems...). }\end{array}$ & & & & & \\
\hline & $\begin{array}{l}\text { Written materials associated with the service (such as } \\
\text { 2. pamphlets, brochures, websites...) should be visually } \\
\text { appealing in an excellent airline. }\end{array}$ & & & & & \\
\hline & $\begin{array}{l}\text { Employees should be neatly appearing in excellent } \\
\text { airlines. }\end{array}$ & & & & & \\
\hline \multirow{3}{*}{ Reliability } & $\begin{array}{l}\text { Excellent airlines should perform the service right the } \\
\text { first time (error-free record). }\end{array}$ & & & & & \\
\hline & $\begin{array}{l}\text { Excellent airlines should provide their services at the } \\
\text { time they promise to do so. }\end{array}$ & & & & & \\
\hline & $\begin{array}{l}\text { Excellent airline should show a sincere interest in } \\
\text { solving the problems that customers have. }\end{array}$ & & & & & \\
\hline \multirow{3}{*}{ Responsiveness } & $\begin{array}{l}\text { Employees in excellent airlines should always be } \\
\text { 7. willing to help customers and to respond to their } \\
\text { requests all the time. }\end{array}$ & & & & & \\
\hline & $\begin{array}{l}\text { Employees in excellent airlines should give timely } \\
\text { prompt service to customers. }\end{array}$ & & & & & \\
\hline & $\begin{array}{l}\text { Excellent airlines should make information easily- } \\
\text { obtainable by customers. }\end{array}$ & & & & & \\
\hline
\end{tabular}




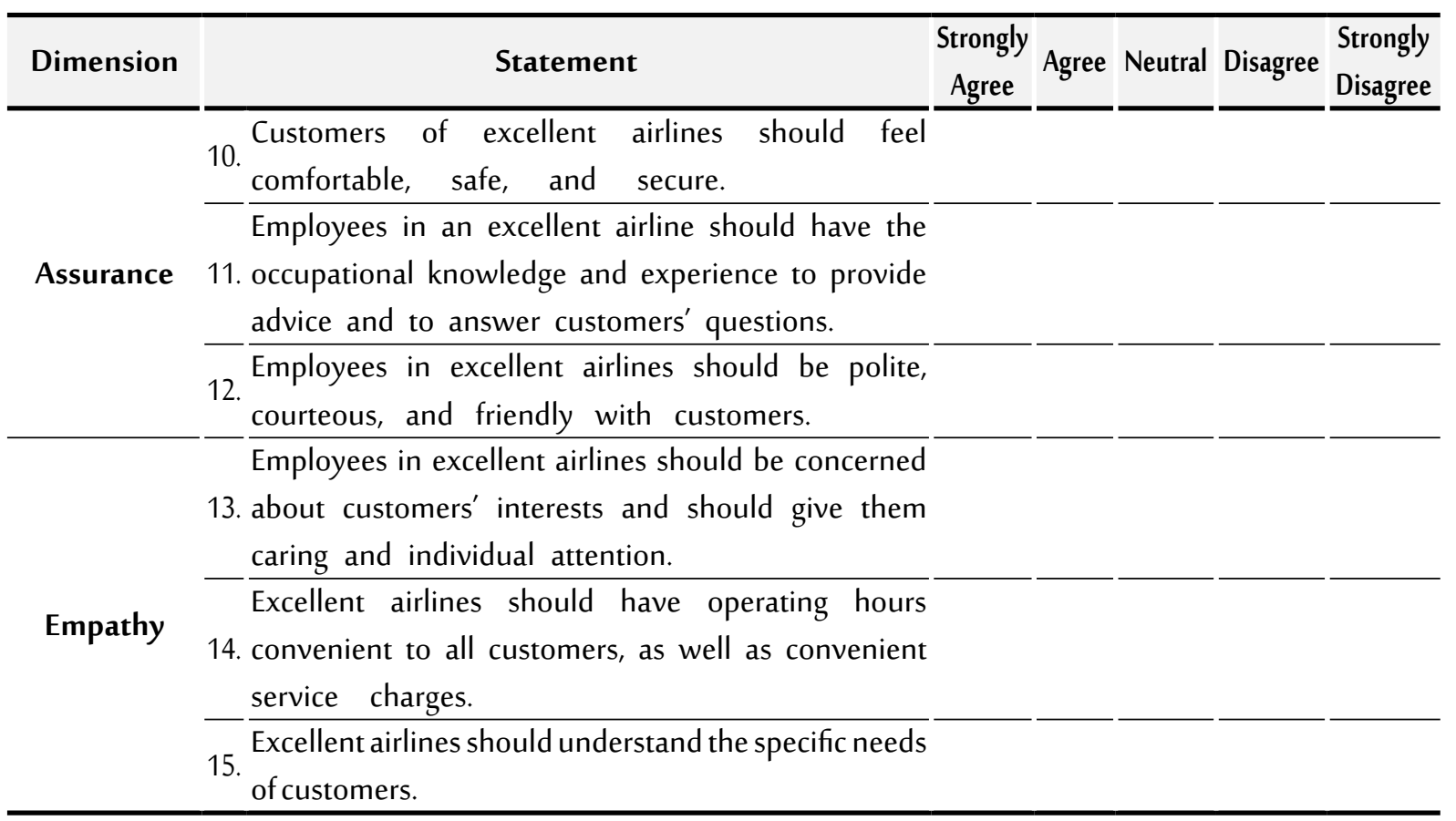

16. Please (arrange) the following features according to the importance of each to you, using the numbers from 1 to 5 :

- The appearance of the airline's equipment, communication materials, and personnel. (........)

- The airline's ability to perform the promised service dependably and accurately. (........)

- The airline's willingness to help customers and to provide prompt service. (.........)

- The knowledge and courtesy of the airline's employees and their ability to convey trust and confidence. (.........)

- The caring and personal attention the airline provides customers. (.........)

\section{Third/Customer Perception:}

Directions: The following set of statements is related to your feelings about EgyptAir particularly. Please show the extent to which you believe EgyptAir has the feature described by each statement. Your choice will truly reflect your perceptions about EgyptAir.

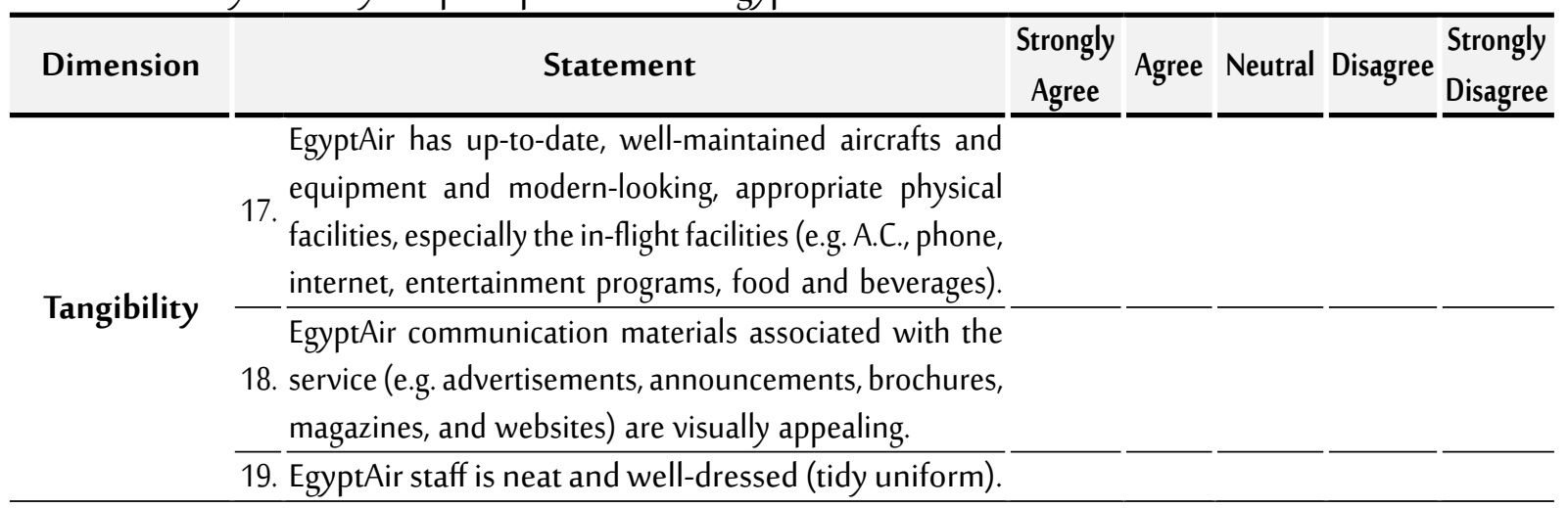




\begin{tabular}{|c|c|c|c|c|c|c|}
\hline Dimension & Statement & $\begin{array}{c}\text { Strongly } \\
\text { Agree }\end{array}$ & Agree & Neutral & Disagree & $\begin{array}{l}\text { Strongly } \\
\text { Disagree }\end{array}$ \\
\hline \multirow{3}{*}{ Reliability } & $\begin{array}{l}\text { EgyptAir has easy or simple processes and accurate } \\
\text { 20. booking records and can perform the service right the } \\
\text { first time. }\end{array}$ & & & & & \\
\hline & $\begin{array}{l}\text { 21. EgyptAir provides their services at the promised time } \\
\text { (e.g. scheduled flights depart and arrive on-time). }\end{array}$ & & & & & \\
\hline & $\begin{array}{l}\text { When you have a complaint/ problem (particularly } \\
\text { 22. boarding problems), EgyptAir shows patience and } \\
\text { sincere interest in resolving it. }\end{array}$ & & & & & \\
\hline \multirow{3}{*}{ Responsiveness } & $\begin{array}{l}\text { Employees of EgyptAir are always willing to help you } \\
\text { 23. and capable to respond to your requests, even in } \\
\text { unexpected/ emergency situations while boarding. }\end{array}$ & & & & & \\
\hline & $\begin{array}{l}\text { Employees of EgyptAir give you speedy and efficient } \\
\text { 24. service (e.g. reservation, baggage handling, check-in, } \\
\text { and in-flight services). }\end{array}$ & & & & & \\
\hline & $\begin{array}{l}\text { EgyptAir makes information (about their services, } \\
\text { 25. flights, and changes in prices) accessible and you can } \\
\text { reach it easily. }\end{array}$ & & & & & \\
\hline \multirow{3}{*}{ Assurance } & $\begin{array}{l}\text { You feel confident, safe, and secure with EgyptAir (e.g. less } \\
\text { 26. probability of flight breakdown, precise luggage transport, } \\
\text { safety instructions, clean and comfortable interior/ seat). }\end{array}$ & & & & & \\
\hline & $\begin{array}{l}\text { Employees at EgyptAir are well-trained and have the } \\
\text { 27. skills (e.g. language skills), knowledge, and experience } \\
\text { to provide advice and to answer your questions. }\end{array}$ & & & & & \\
\hline & $\begin{array}{l}\text { Employees of EgyptAir are polite, courteous, and } \\
\text { friendly with you. }\end{array}$ & & & & & \\
\hline \multirow{6}{*}{ Empathy } & $\begin{array}{l}\text { Employees at EgyptAir are concerned about your } \\
\text { interests and give you caring and individual attention. }\end{array}$ & & & & & \\
\hline & $\begin{array}{l}\text { EgyptAir has convenient operating hours and flight } \\
\text { schedules, as well as enough frequencies, numerous } \\
\text { ticketing channels, reasonable prices, sufficient } \\
\text { compensations, and internal transportation. }\end{array}$ & & & & & \\
\hline & $\begin{array}{l}\text { EgyptAir understands your specific needs (e.g. having } \\
\text { 31. travel-related partners, such as car rentals, hotels, and } \\
\text { travel insurance). }\end{array}$ & & & & & \\
\hline & $\begin{array}{l}\text { 32. Generally, you are satisfied with the services offered } \\
\text { by EgyptAir. }\end{array}$ & & & & & \\
\hline & 33. You will continue to use EgyptAir in the future. & & & & & \\
\hline & $\begin{array}{l}\text { You will recommend travelling with EgyptAir to your } \\
\text { friends and relatives. }\end{array}$ & & & & & \\
\hline
\end{tabular}

